УДК 655.3.026

๑ О. О. Гриценко (Сарапулова), асистент, О. Д. Задорожна, магістрантка, В. П. Шерстюк, д.Х.н., професор, НТУУ «КПІ», Київ, Україна

\title{
ВИЗНАЧЕННЯ ОПТИЧНИХ ХАРАКТЕРИСТИК ЗОБРАЖЕНЬ 3 НАНОФОТОННИМИ ЕЛЕМЕНТАМИ, ВИГОТОВЛЕНИХ СТРУМИННИМ СПОСОБОМ ДРУКУ
}

У статті досліджено вплив технологічних факторів на оптичні характеристики друкованих зображень з нанофотонними елементами, виготовлених струминним способом друку.

Розроблено математичну модель, яка дає можливість шляхом зміни значень досліджених факторів створювати за допомогою струминного друку зображення з нанофотонними елементами із наперед заданими оптичними характеристиками.

Ключові слова: струминний друк; оптичні характеристики; новітні функціональні паковання; конверти для цінних паперів; фотолюмінесценція; нанофотонні елементи.

\section{Постановка проблеми}

Зображення $з$ нанофотонними елементами являють собою друковані ділянки, нанесені за допомогою класичних способів друку з використанням фарб, які містять нанофотонні компоненти - тобто матеріали, які базуються на явищах випромінювання та поглинання світла компонентами у нанометровому масштабі. Такі фарби і, відповідно, надруковані ними зображення не лише відбивають, а і випромінюють світло внаслідок поглинання світлової енергії, тобто мають фотолюмінесцентні властивості. До оптичних характеристик друкованих зображень з нанофотонними елементами, які мають фотолюмінесцентні властивості, слід віднести інтенсивність люмінесценції та колірні ха- рактеристики. Інтенсивність фотолюмінесценції відбитків, які поглинають і випромінюють світло (емісійні процеси), аналогічна оптичній густині відбитків, які поглинають і відбивають світло (абсорбційні процеси). Такі матеріали можуть мати змінні оптичні характеристики, а саме змінювати колір та/або інтенсивність фотолюмінесценції в певних умовах, зазвичай у контакті з деякими речовинами у певній концентрації, наприклад, з речовинами, які утворюються внаслідок процесів псування харчових продуктів. Завдяки цьому фарби з нанофотонними компонентами можна використовувати для виготовлення не тільки захищеної від підробки поліграфічної продукції, а і для функціональних паковань. 


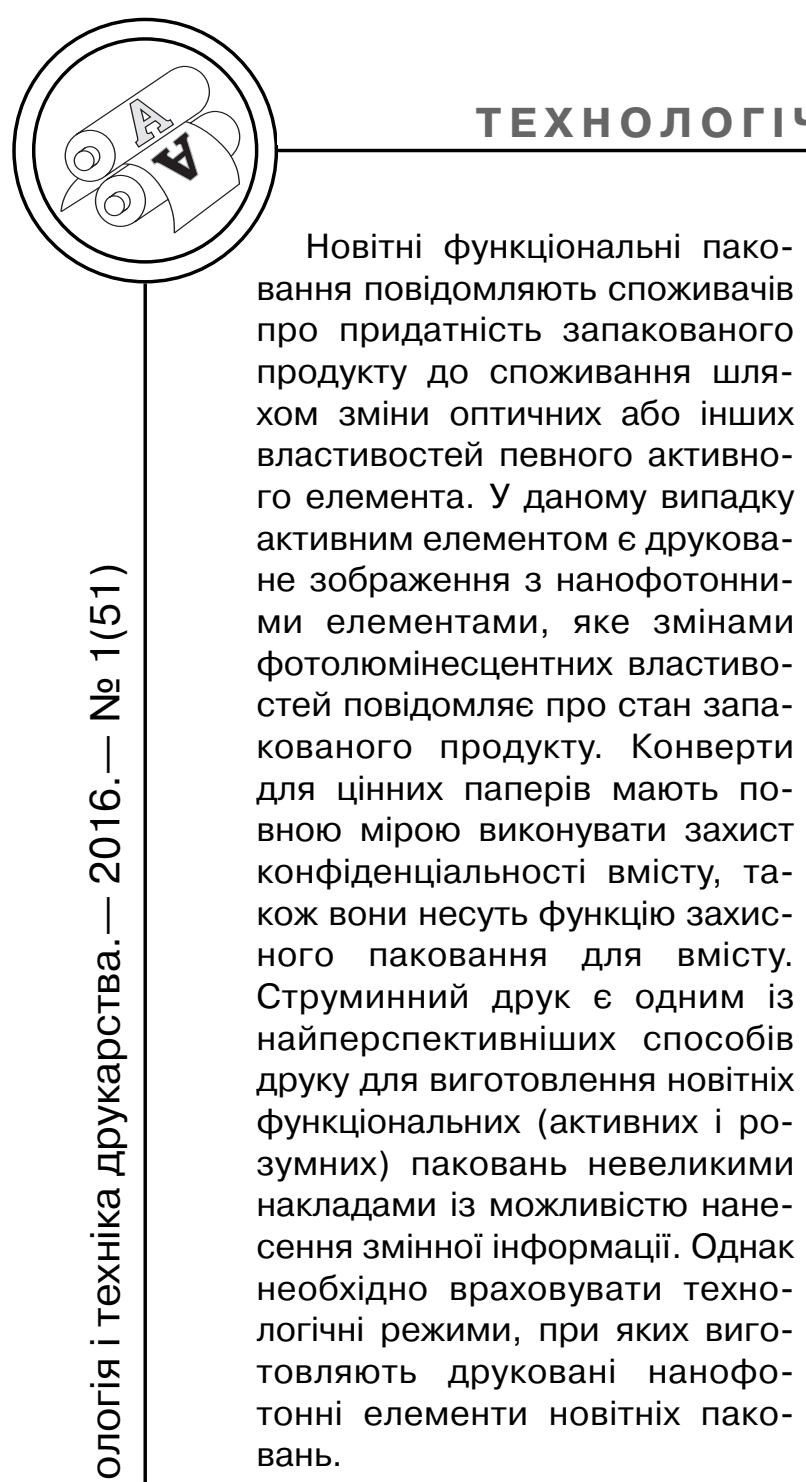

\section{Аналіз попередніх досліджень}

Аналіз інформації, яка на даний час наявна в літературних джерелах, свідчить про те, що питання врахування впливу технологічних факторів процесу виготовлення друкованих зображень 3 нанофотонними елементами для новітніх паковань на їхні фотолюмінесцентні характеристики $€$ недостатньо розкритим. Наявні результати досліджень складу фарб з нанофотонними елементами [1, 2], виготовлення зображень 3 нанофотонними елементами тра- фаретним і тампонним способами друку [3, 4]. Зважаючи на вищесказане, необхідними $€$ дослідження впливу технологічних факторів струминного друку на фотолюмінесцентні характеристики друкованих зображень 3 нанофотонними елементами для новітніх паковань 3 метою виготовлення зображень з наперед заданими оптичними характеристиками.

\section{Мета роботи}

Метою роботи є встановлення впливу факторів технологічного процесу струминного друку на процес виготовлення друкованих зображень 3 нанофотонними елементами для новітніх функціональних паковань, конвертів для цінних паперів та на їхні оптичні (фотолюмінесцентні) характеристики.

\section{Результати проведених досліджень}

Для виготовлення фарб з нанофотонними елементами було використано колоїдні розчини наночастинок оксиду цинку (ZnO) в етанолі і полівінілпіролідон (ПВП) з молекулярною масою 360000 г/моль згідно з методикою, викладеною в [1]. За допомогою розроблених фарб було надруковано тонові зображення з різним відсотком градацій у вигляді квадратів розмірами $2 \times 2$ см на папір різної гладкості за допомогою струминного способу друку. Було використано струминний принтер HP Photosmart С3183, з роздільною здатністю 600 dрі. Спектри фотолюмінесценції, за якими визначали інтегральну інтенсивність люмі- 
несценції відбитків, було записано за допомогою флуоресцентного спектрометра Perkin Elmer LS 55, за однакових умов вимірювань - довжина хвилі світла збудження люмінесценції $\lambda=330$ нм, оптична ширина щілин 10 нм і 5 нм, швидкість сканування 600 нм/хв., емісійний фільтр при 350 нм. Для кожного зразку було проведено 5 вимірювань, на основі яких було визначене середнє значення інтенсивності люмінесценції $\mathrm{y}_{\text {cep. }}$.

Було досліджено вплив наступних факторів на інтенсивність люмінесценції одержаних друкованих зображень (інтегральну, у короткохвильовій 400 нм і довгохвильовій 525 нм зонах): концентрація нано-ZnO; концентрація ПВП; відсоток градацій; гладкість поверхні паперу.
Оскільки звичайні папери містять у своєму складі оптичні відбілювачі (optical brightness agents), які світяться (люмінесціюють) під дією УФ світла, для досліджень було використано папери без оптичних відбілювачів (non-OPA papers). У табл. 1 наведено марки використаних для досліджень паперів та деякі їхні технічні характеристики.

Для одержання аналітичної залежності інтенсивності люмінесценції відбитків I =f(cz, cp, r, s), яка враховує вплив вищевказаних факторів на інтенсивність люмінесценції друкованого шару на відбитку, було проведено повний факторний експеримент [5-7] і створено математичну модель.

Відомості про області визначення факторів і області визначення та інтересу, представлені у табл. 2.

Таблиця 1

Використані папери

\begin{tabular}{|c|c|c|c|}
\hline Виробник, назва & Maca $1 \mathrm{M}^{2}$ & Гладкість, с & Товщина, мкм \\
\hline \multicolumn{4}{|c|}{ Папір для струминного друку } \\
\hline Epson Hot Press Natural & 330 & 250 & 170 \\
\hline Red River Duro SoftGloss Rag & 310 & 300 & 165 \\
\hline Arches Bright White Hot Press 140 & 300 & 350 & 157 \\
\hline Premier Fine Art Smooth Hot Press & 270 & 400 & 148 \\
\hline Red River Aurora Art Natural & 250 & 400 & 136 \\
\hline Premier Fine Art Platinum Rag & 285 & 500 & 140 \\
\hline Moab Entrada Rag Natural 190 & 190 & 500 & 155 \\
\hline Epson Premier Art Scrapbook & 205 & 600 & 124 \\
\hline \multicolumn{4}{|c|}{ Газетний папір } \\
\hline ОАО «Кондопога», Росія & 45 & 65 & 80 \\
\hline $\begin{array}{l}\text { Fabryka Papieru Myszkow Sp. z O.O., } \\
\text { Польща }\end{array}$ & 45 & 70 & 80 \\
\hline $\begin{array}{l}\text { ОАО «Монді Сиктивкарський ЛПК», } \\
\text { Росія }\end{array}$ & 45 & 70 & 80 \\
\hline
\end{tabular}




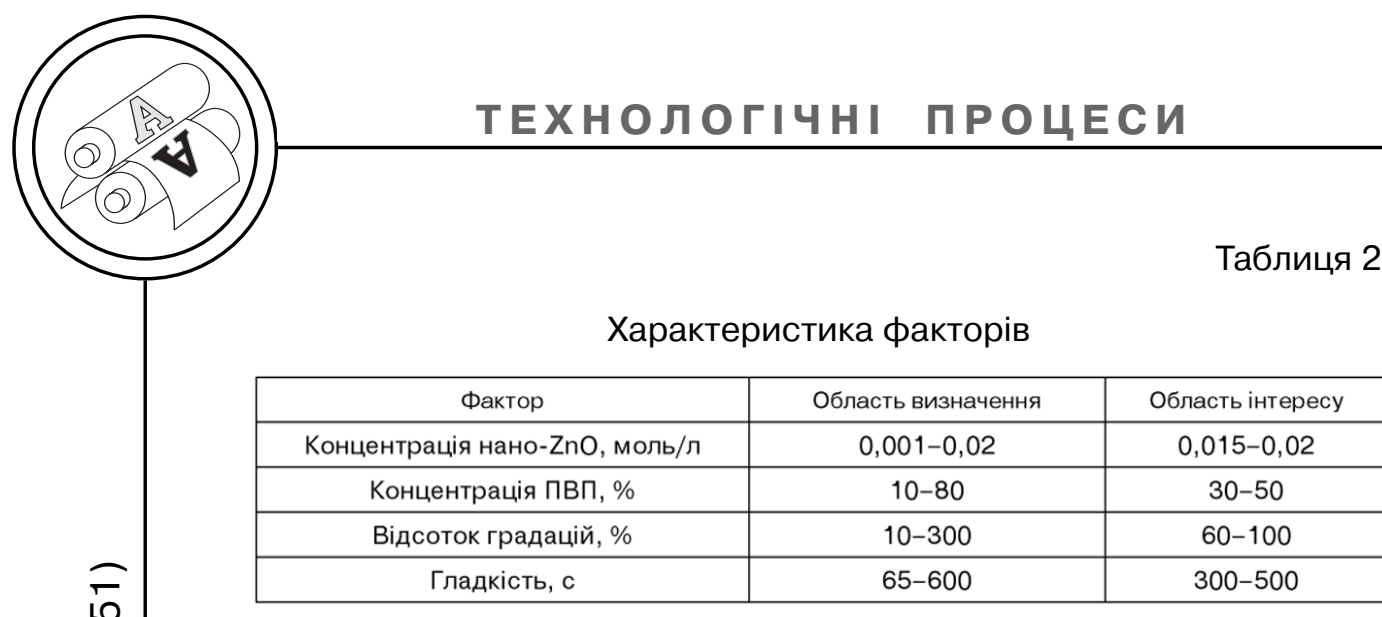

Вибір основного рівня та інтервалів варіювання експериментального дослідження. Для кожного фактору необхідно вибрати два рівня, на яких він буде варіюватись під час експерименту. Концентрація нано-ZnO змінювалася в межах 0,0010,02 моль/л. Останнє значення $€$ максимально можливою концентрацією колоїдного розчину наночастинок ZnO в етанолі, яку можливо одержати, згідно 3 літературними даними [8] у даних умовах. Для одержання найбільшої інтенсивності люмінесценції відбитка необхідне використання максимально можливих концентрацій люмінесцентної складової, тому інтервал варіювання доцільно обрати в межах 0,015-0,02 моль/л.

Концентрацію ПВП можливо змінювати в межах 10-80 \%. Останнє значення $€$ максимально можливою концентрацією ПВП у зв'язку тим, що більші концентрації призводять до перевищення технологічно необхідної в'язкості фарб струминного друку і до неможливості здійснення процесу друкування. Попередні дослідження показали, що найкращі результати одержують із використанням концентрації ПВП в межах 30-50 \%, тому було встановлено даний інтервал варіювання.
Відсоток градацій тонового зображення змінювався в межах 10-300 \%. Значення до 100 \% одержувалися шляхом зміни задрукованої площі растрового зображення. Значення, які перевищують $100 \%$, одержували шляхом повторного задруковування суцільних ділянок. Максимальне значення одержано трикратним задруковуванням суцільної ділянки. Для виготовлення новітніх функціональних паковань та конвертів зображення 3 нанофотонними елементами зазвичай матимуть відсоток градацій в межах 60-100\%, що і було обрано для інтервалу варіювання.

Гладкість паперу і картону товщиною до 0,6 мм вимірюється за методом Бекка і полягає у вимірюванні часу проходження певного об'єму повітря у вакуумну камеру між поверхнею зразка і поверхнею скляної полірованої пластини у визначених умовах [9]. Гладкість поверхні паперу було одержано із технічних специфікацій використаних марок паперу (табл. 1) і змінювалася в межах 65-600 с. Оскільки більшість паперів без оптичних відбілювачів мають гладкість в межах 300-500 с, то інтервал варіювання для цього параметру доцільно вибрати в 


\section{ТЕХНОЛОГІЧНІ ПРОЦЕСИ}

Таблиця 3

Рівні та інтервали варіювання факторів

\begin{tabular}{|c|c|c|c|c|}
\hline \multirow{2}{*}{ Рівні } & \multicolumn{4}{|c|}{ Фактори } \\
\cline { 2 - 5 } & $\begin{array}{c}\mathrm{x}_{1} \\
\text { (концентрація } \\
\text { нано-ZnO) }\end{array}$ & $\begin{array}{c}\mathrm{x}_{2} \\
\text { (концентрація } \\
\text { ПВП) }\end{array}$ & $\begin{array}{c}\mathrm{x}_{3} \\
\text { (відсоток } \\
\text { градацій) }\end{array}$ & $\begin{array}{c}\mathrm{x}_{4} \\
\text { (гладкістьповерхні } \\
\text { паперу) }\end{array}$ \\
\hline Основний & 0,0175 & 40 & 80 & 400 \\
\hline $\begin{array}{c}\text { Інтервал } \\
\text { варіювання }\end{array}$ & 0,0025 & 10 & 20 & 100 \\
\hline Верхній & 0,02 & 50 & 100 & 500 \\
\hline Нижній & 0,015 & 30 & 60 & 300 \\
\hline
\end{tabular}

цих межах. Вказані дані наведено в табл. 3.

Для реалізації всіх можливих поєднань рівнів факторів для лінійної моделі необхідно провести кількість досліджень:

$$
N=2^{n}=2^{4}=16,
$$

де $\mathrm{n}$ - кількість факторів, 2 кількість рівнів.

Проведемо нормування факторів. Верхнім значенням факторів присвоюємо нормоване значення +1 , нижнім значенням - нормоване значення -1. Матриця повного факторного експерименту для 16 досліджень, із врахуванням ефекту взаємодії факторів, наведена у табл. 4.

У результаті проведених експериментальних досліджень було створено математичну модель I = f(cz, cp, R, s).

Коефіцієнти рівняння в нормованих координатах розраховувались за формулою $[5,6]$ :

$$
\tilde{a}_{k}=\frac{1}{2^{n}} \sum_{i=1}^{2^{n}} y_{i} \tilde{x}_{k i}(k=0 . . n) .
$$

Одержане рівняння математичної моделі у нормованих координатах має вигляд:

$$
\begin{gathered}
y\left(\tilde{x}_{1}, \tilde{x}_{2}, \tilde{x}_{3}, \tilde{x}_{4}\right)=10,0156 \tilde{x}_{1}+ \\
+5,0156 \tilde{x}_{2}+29,7968 \tilde{x}_{3}+
\end{gathered}
$$

$+44,8594 \tilde{x}_{4}-0,2031 \tilde{x}_{1} \cdot \tilde{x}_{2}+$ $+0,0781 \tilde{x}_{1} \cdot \tilde{x}_{3}+0,0781 \tilde{x}_{1} \cdot \tilde{x}_{4}+$ $+0,0781 \tilde{x}_{2} \cdot \tilde{x}_{3}-0,2344 \tilde{x}_{2} \cdot \tilde{x}_{4}-$ $-0,0781 \tilde{x}_{3} \cdot \tilde{x}_{4}+0,1719 \cdot \tilde{x}_{1} \cdot \tilde{x}_{2}$. $\cdot \tilde{x}_{3}-0,0469 \tilde{x}_{1} \cdot \tilde{x}_{3} \cdot \tilde{x}_{4}+$ $+0,0469 \tilde{x}_{1} \cdot \tilde{x}_{2} \cdot \tilde{x}_{4}+0,2656 \tilde{x}_{2}$. $\cdot \tilde{x}_{3} \cdot \tilde{x}_{4}+0,1094 \tilde{x}_{1} \cdot \tilde{x}_{2} \cdot \tilde{x}_{3} \cdot \tilde{x}_{4}+$ $+152,30$.

Для переходу від нормованих до ненормованих факторів знаходимо параметри моделі для ненормованих координат:

$$
\begin{aligned}
& a_{0}=\tilde{a}_{0}-\sum_{i=1}^{n} \tilde{a}_{i} \frac{x_{i B}+x_{i H}}{x_{i B}-x_{i H}} ; \\
& a_{k}=\frac{2 \tilde{a}_{k}}{x_{k B}-x_{k H}}(k=1 \ldots n) .
\end{aligned}
$$

де $x_{i в}-$ верхнє значення і-го фактора, $\mathrm{x}_{\mathrm{iH}}-$ нижнє значення і-го фактора.

У результаті отримаємо модель в ненормованих координатах:

$\mathrm{I}=2275,27432 \mathrm{cz}+0,284853 \mathrm{cp}+$ $+0,846129 \mathrm{R}+0,25477 \mathrm{~s}-$ $-4,614441 \mathrm{cz} \cdot \mathrm{cp}+0,887392 \mathrm{cz}$.

$\cdot R+0,177479 \mathrm{cz} \cdot \mathrm{s}+0,000222 \mathrm{cp}$. - R - 0,000133 cp.s - 0,000022 R. $\cdot s+0,195226 \mathrm{cz} \cdot \mathrm{cp} \cdot \mathrm{R}-0,005324 \mathrm{cz}$.

$\cdot R \cdot \mathrm{s}+0,010649 \mathrm{cz} \cdot \mathrm{cp} \cdot \mathrm{s}+$ $+0,000007 \mathrm{cp} \cdot \mathrm{R} \cdot \mathrm{s}+0,001242 \mathrm{cz}$. $\cdot c p \cdot R \cdot s+152,30$, 


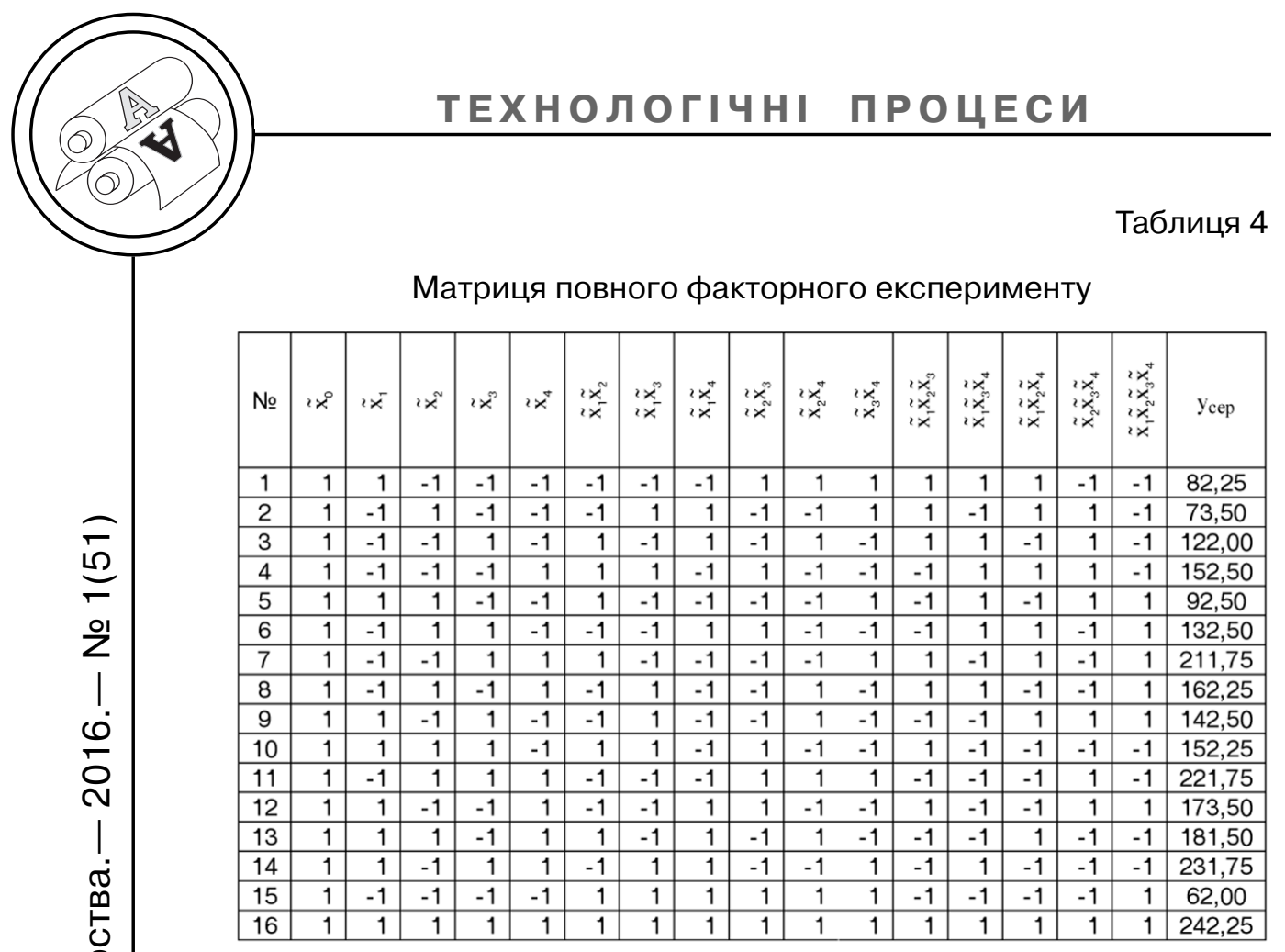

де $\mathrm{cz}$ - концентрація нано-ZnO, моль/л, ср - концентрація ПВП, $\%, r$ - відсоток градацій тонового зображення, \%, s гладкість поверхні паперу, с.

Отже, було виявлено вплив технологічних факторів струминного способу друку на оптичні характеристики друкованих зображень з нанофотонними елементами. Найбільший вплив на інтенсивність люмінесценції мають гладкість поверхні паперу і відсоток градацій тонового зображення. Чим вища гладкість поверхні паперу і чим більше відсоток градацій тонового зображення наближається до 100 \%, тим вище інтенсивність люмінесценції одержуваного друкованого зображення. Менший вплив у вибраному інтервалі варіювання здійснює концентрація люмінесцентної складової у фарбі, проте це пов'язано із тим, що доцільно обирати найвищу кон- центрацію люмінесцентної складової для найвищої інтенсивності люмінесценції, а при підвищенні концентрації при високих значеннях концентрацій нанофотонної речовини (нано$\mathrm{ZnO})$, не відбувається значного підвищення інтенсивності люмінесценції одержуваного друкованого зображення. Найменший вплив має концентрація ПВП у фарбі, оскільки за обраного інтервалу варіювання ПВП достатньо забезпечує стабілізацію нанофотонної речовини у фарбі.

\section{Висновки}

Таким чином, було досліджено вплив факторів технологічного процесу друкування струминним способом друку на оптичні характеристики одержуваних друкованих зображень 3 нанофотонними елементами для новітніх функціональних паковань та конвертів для цінних па- 
перів. Було виявлено, що при збільшенні значень усіх досліджуваних факторів інтенсивність люмінесценції відбитку збільшується, проте найбільший вплив на інтенсивність люмінесценції мають гладкість паперу і відсоток градацій. За допомогою розробленої математичної моделі впливу технологічних факторів (концентрації складових фарби з нанофотонними елементами, відсотку градацій тонового зображення, гладкості поверхні паперу), можна шляхом зміни факторів, у тому числі технологічних факторів струминного друку, створювати друковані зображення 3 нанофотонними елементами із наперед заданими оптичними характеристиками.

Дослідження проводилися за підтримки Міністерства освіти і науки України в рамках НДР № 2873п. Публікація містить результати досліджень, проведених при грантовій підтримці Державного фонду фундаментальних досліджень за конкурсним проектом Ф64/10-2016 від 28.03.16.

\section{Список використаної літератури}

1. Шерстюк В. П. Люминесцентные пленки на основе наноразмерного оксида цинка в поливинилпирролидоне и их функциональные характеристики / В. П. Шерстюк, В. В. Швалагин, О. О. Сарапулова, В. М. Гранчак // VI Международная научная конференция «Функциональная база наноэлектроники». Сборник научных трудов. - Харьков : ХНУРЭ, 2013. - 393 с. - C. 250-253.

2. Сарапулова О. О. Проблеми поліграфічного виготовлення новітніх паковань з нанорозмірними фотоактивними елементами / О. О. Сарапулова, В. П. Шерстюк // Технологія і техніка друкарства. - 2013. - № 2. С. 46-57. - Режим доступу : http://ttdruk.vpi.kpi.ua/article/view/30734.

3. Сарапулова О. О. Технологічні особливості нанесення нанофотонних елементів паковань трафаретним способом друку / О. О. Сарапулова, В. П. Шерстюк // Технологія і техніка друкарства. - 2013. - № 3. - С. 18-26. - Режим доступу : http://ttdruk.vpi.kpi.ua/article/view/23515.

4. Сарапулова О. Особливості відтворення нанофотонних міток тампонним способом друку / О. Сарапулова, В. Шерстюк // Матеріали доповідей XVIII Міжнародної науково-практичної конференції з проблем видавничополіграфічної галузі. - 2014. - С. 56-58.

5. Жирабок А. Н. Планирование эксперимента для построения математических моделей / А. Н. Жирабок // Соросовский образовательный журнал. - 2001. - № 9. - С. 121-127.

6. Адлер Ю. П. Планирование эксперимента при поиске оптимальных условий / Ю. П. Адлер, Е. В. Маркова, Ю. В. Грановский. - М. : Наука, 1976. -280 с.

7. Зедгинидзе И. Г. Планирование эксперимента для исследования многокомпонентных систем / И. Г. Зедгинидзе. - М. : Наука, 1976. - 390 с.

8. Shvalagin V. V. Role of quantum-sized effects on the cathodic photocorrosion of ZnO nanoparticles in ethanol / V. V. Shvalagin, O. L. Stroyuk, S. Ya. Kuchmii // Theoretical and Experimental Chemistry. - 2004. - Vol. 40(6). P. 378-382.

9. Папір та картон. Метод визначення гладкості (метод Бекка) : Дсту 3439-96 (ГОСТ 12795-97) (ISO 5627:1995). — [Чинний від 01.01.1996]. — К. : Держстандарт України, 1996. - 12 с. 


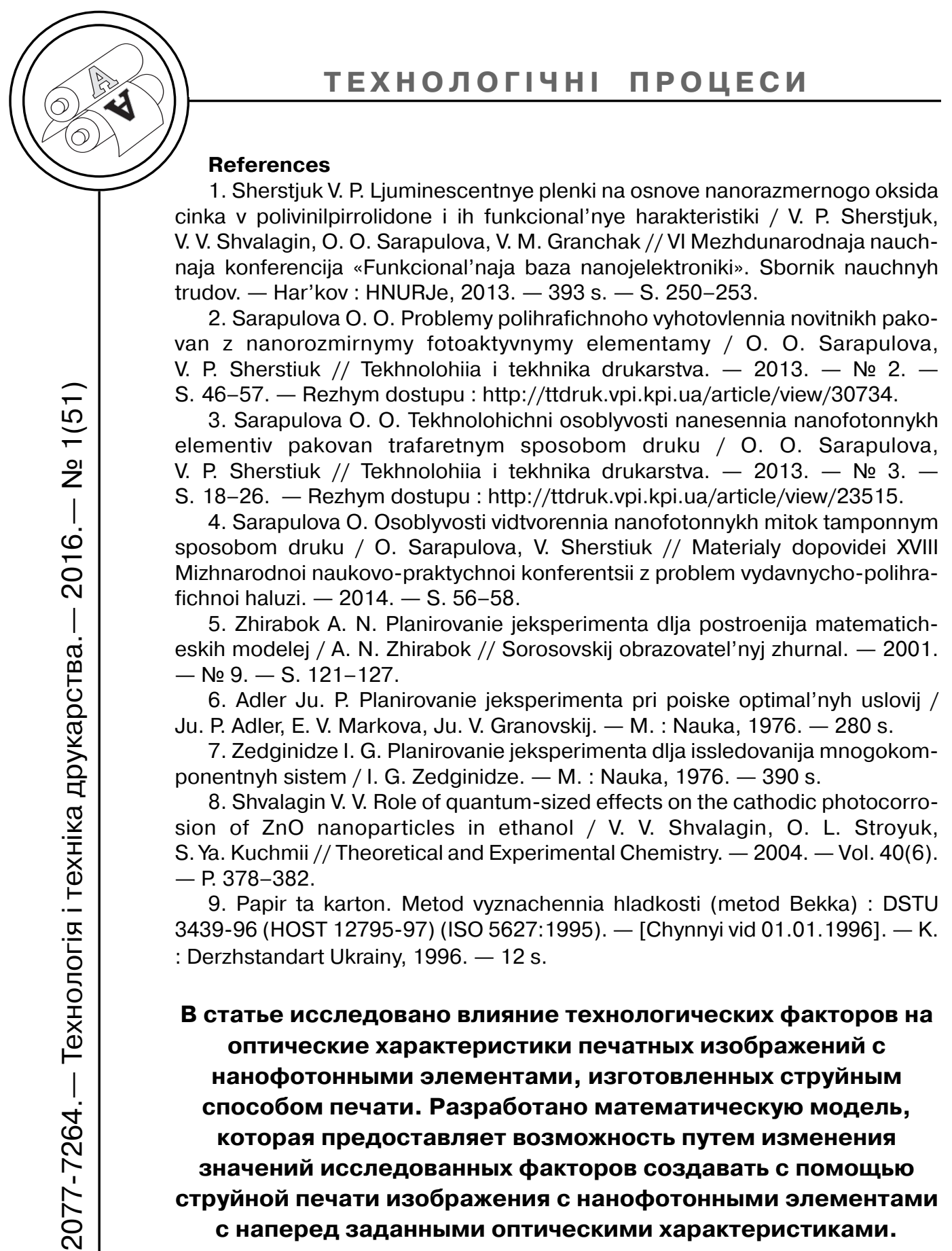

In this paper there is investigated the influence of technological parameters on optical characteristics of printed images with 
nanophotonic elements produced by inkjet printing. The mathematical model is developed which allows, by changing values of the investigated factors, using inkjet printing for production of printed images with nanophotonic elements with predetermined optical characteristics.

Keywords: inkjet printing; optical characteristics; envelopes for security printing; smart functional packaging; photoluminescence; nanophotonic elements.

Рецензент - Т. А. Роїк, д.т.н., професор, НТУУ «КПІ»

Надійшла до редакції 02.12.15 